\title{
Psicanálise e neurociências
}

Antonio Carlos Pacheco e Silva Filho ${ }^{1}$

Infelizmente, existe uma tendência no meio médico e mesmo no psiquiátrico que julga haver um antagonismo entre os progressos sobre o conhecimento do cérebro e a teoria psicanalítica de nossos dias, já bem diferente em muitos pontos dos postulados freudianos. Entretanto, não é questão de uma ou outra, mas de uma e outra, como procurarei mostrar.

$\mathrm{O}$ conceito atual neurocientífico de plasticidade cerebral, das redes ou mapas neuronais com suas miríades de sinapses sempre em mudança de maneira ativa em contato com aquilo que vem da realidade interna e externa, dá uma base orgânica estrutural para a teoria e prática psicanalíticas atuais. A neurociência vem mostrando como o estar consciente depende da sincronização, da sintonia entre várias estruturas corticais e subcorticais.

O inconsciente (fantasia inconsciente), por sua vez, dependeria, para se manifestar, de um bloqueio emocional de certos conjuntos neuronais e suas sinapses, liberando outras redes, mais ligadas ao mundo interno, em uma espécie de neo-jacksonismo. Tal se passaria no sonho, nos lapsos de língua, nas parapraxias e na construção de sintomas neuróticos e psicóticos, conforme já Freud havia observado. O ser humano necessita da fantasia, tanto consciente como inconsciente, em alternância perene entre essa realidade interna e o mundo exterior. Ambas são necessárias à mente, para dar "alma" ao cérebro, sem as quais este morreria.

O pensar parece ser em grande parte uma sintonia entre a fantasia inconsciente, as captações sensoriais aferentes (o cérebro não sobreviveria sem o corpo) e os engramas (memórias) estabelecidos no decorrer da vida. Dormir seria necessário para descansar certos setores sinápticos, ligados à realidade exterior, deixando livres outros mais conectados ao mundo interno, originando o sonhar. Sem esse desligamento neurossináptico da consciência vígil, o cérebro não sobrevive. Os especialistas em sono sabem disso.

Para o aprendizado (aquisição de novos engramas), o sono bem dormido é tão necessário, mostrando pesquisas com estudantes, quanto a primeira metade da noite é fundamental para consolidar o aprendido em vigília (Houzel, 2002). Provavelmente seria porque no sono profundo inicial funciona mais a realidade interna, ao contrário do sono superficial, com a realidade externa mais influente, entrando nos sonhos. Não é impossível que, para a consolidação do aprendizado, seja necessário o que em psicanálise se denomina autismo construtivo, a mente fica voltada para dentro, para si mesma com seus objetos internos, sem sonhos e contatos com o mundo exterior. Isso poderá explicar certos lampejos criativos, tanto artísticos como científicos. $\mathrm{Na}$ química, quando Kekulé sonhou com o anel benzênico, ainda não conceituado, e na fisiologia quando Banting sonhou necessitar ligar o canal pancreático de cães para confirmar que as ilhotas de Langermans secretavam a insulina.

Houzel, ao analisar a motivação onírica (um dos pilares da psicanálise freudiana), não inclui o fator emocional, a realização dos desejos e o repetir uma situação traumática na tentativa de sobrepujá-la. Também, quando revela depender a memória da riqueza de estímulos que aumentam as sinapses do hipocampo, não faz qualquer referência à motivação (tanto consciente como inconsciente), não só bloqueando sentimentos indesejáveis das lembranças como estimulando outros, e a atenção. Por isso, provavelmente os deprimidos crônicos menos motivados, procurando menos estímulos internos e externos, são mais suscetíveis à "falta de memória" e por isso provavelmente serem mais propensos à doença de Alzheimer.

Ainda Houzel, ao analisar o bocejo do ponto de vista neurocientífico, o faz demasiadamente apegado a esse campo, não incluindo em suas observações fatores emocionais interpessoais (objeto da psicanálise atual). Realmente o bocejo pode ter várias conotações, além das mencionadas pela autora, como disfarçar uma situação em que a pessoa é criticada, em comunicação inconsciente de algo como: "Não estou nem aí". Até na psicologia canina, muitas vezes parecida com a humana, pode se observar um cão censurado pelo dono olhar para o outro lado e bocejar, como que comunicando ao primeiro "Isso não me afeta, não é comigo, não me interessa."

Houzel, no capítulo "Lembrando o que não aconteceu" de seu livro, a falta de ênfase no emocional é patente. Muitas lembranças e falsas lembranças , como o "déjà vu" são incrementadas quando o fato vivido ou imaginado causou maior impacto afetivo. Além disso, com a repressão (recalque) emocional de um fato traumático vivido ou fantasiado, a rememoração mostra que a pessoa não tinha qualquer consciência de sua existência. A revivescência de conflitos emocionais e a compreensão desta na transferência em sessão analítica alteraram certas marcas cerebrais em um sentido positivo, alargando horizontes da pessoa sobre si mesma

\footnotetext{
Doutor em Medicina do Departamento de Psiquiatria da USP. Membro efetivo e analista didata da Sociedade Brasileira de Psicanálise de São Paulo. Graduated Fellow do Institute of Living, Hartford, Conn. EUA.

Endereço para correspondência:

Rua Padre Saliba, 9, São Paulo, SP - CEP 01444-010
} 
e seus relacionamentos. Pugh (2002) cita pesquisas a respeito. Conseqüentemente aparece maior paz interna, menor ansiedade, diminuição dos sintomas clínicos e maior integração emocional. Para ocorrerem tais mudanças na plástica cerebral é indispensável a assiduidade do contato analítico (três a cinco vezes por semana) durante anos, para se tornarem duradouras.

Comentando as bases cerebrais do humor, Houzel cita pesquisas atuais através do mapeamento de zonas ativas do cérebro revelarem que anedotas relacionadas com o significado das palavras ativam centros da linguagem no lobo temporal. Por sua vez os trocadilhos ativam o córtex préfrontal medial ventral, processando sinapses relacionadas com o som das palavras. $\mathrm{O}$ achar graça dependeria tanto do sentido como do som das palavras. O riso contagioso ativa o núcleo acumbente, também responsável pela sensação prazerosa da maconha e de outros vícios. Mais uma vez nota-se pouca consideração da parte psicológica (emocional), pela qual achase graça quando um impulso reprimido sexual ou agressivo foge subitamente da censura. Redlich e Bingham (1962) analisando, sob esse ponto de vista, cartoons de revistas norteamericanas, mostram como o riso surge no caso de pessoas ridicularizadas, satisfazendo impulsos agressivos e sexuais reprimidos, por exemplo, as crianças e até mesmo os adultos riem dos palhaços por falarem e cometerem asneiras, fazerem coisas desastradas e assim por diante. Sentem-se superiores e no riso descarregam a agressividade contra eles. Na TV, programas como as "videocassetadas", com pessoas sofrendo quedas ridículas e outras situações humilhantes, bem como nas comédias de "pastelão" americanas, com tortas sendo atiradas no rosto do desafeto, os mesmos impulsos são satisfeitos. Tudo relacionado com repressões dos instintos sexuais e agressivos básicos, subitamente liberados com a surpresa do ocorrido no fim do fato risível. Freud já havia estudado esse assunto em $O$ chiste e $o$ inconsciente.

Cada cultura possui também piadas regionais, divertindo mais àqueles a estas pertencentes, por exemplo, as existentes entre os judeus. No Brasil os portugueses são $\mathrm{o}$ alvo predileto de anedotas em desventuras engraçadas, provavelmente por certa agressividade cultural recalcada dos tempos coloniais, e por seus imigrantes, em geral de pouca cultura e ingênuos, pensarem, falarem e atuarem de maneira engraçada, fazendo os brasileiros se divertirem por sentirem-se momentaneamente superiores. Por ironia, um dos maiores neurocientistas atuais, Antonio Damásio, é português, embora radicado nos Estados Unidos, e, no passado, Egas Moniz, introdutor da angiografia cerebral e da psicocirurgia (leucotomia), ganhador do Prêmio Nobel, também era português, mostrando a injustiça da inclusão dos portugueses em situações risíveis.

Damásio (citado por Houzel), estudando principalmente as emoções com experimentos criativos tanto em animais como em humanos, vem confirmando estruturalmente envolverem as emoções, o corpo e o cérebro. Concluiu que se tem primeiro a emoção para depois senti-la. A angústia, por exemplo, é a alteração corporal neurovegetativa com sensação de aperto, "angor" na garganta, taquicardia, suor frio etc. que provoca o sentimento de ansiedade após o cérebro registrar as alterações corporais. Embora a angústia preceda a ansiedade, ambas não existem isoladamente.

No terreno da consciência, Damásio considera três níveis. Primeiro o do proto-self, relacionado com a imagem do corpo no cérebro. Seria o "ego corporal", de Freud. Quando essa imagem muda no relacionamento com o mundo exterior, surgem representações na consciência que, quando se relacionam aos objetos causadores da mudança, fazem aparecer a consciência do Eu Central, a noção "do aqui e agora comigo", a segunda forma de consciência.

Em $O$ erro de Descartes, Damásio, ainda citado por Houzel, procura mostrar como primeiro vem a emoção e depois o pensamento, portanto, não é "penso, logo existo", mas "existo (tenho a noção de existir) e por isso penso". A emoção e a consciência são inseparáveis, como a angústia da ansiedade. Conclui Damásio: quanto mais o self reconhece suas emoções, mais se torna apto para uma melhor adaptação ao mundo interno e externo. É essa exatamente a intenção do psicanalista para com seu paciente: levá-lo a um melhor conhecimento de seus conflitos emocionais inconscientes, a fim de poderem ser, senão resolvidos, pelo menos atenuados.

Houzel refere-se à capacidade da percepção do sentimento em alertar o organismo para a situação provocadora de emoção, incentivando as reações adaptativas mais adequadas. Algo, acrescentaria eu, já existente nos mamíferos superiores, principalmente nos primatas. Apenas nos últimos, a memorização é fugaz (hipotalâmica) não sendo transferida para o córtex préfrontal com a intensidade do ocorrido no Homo sapiens, resultando no pensamento mais sofisticado. Em suma, esses animais superiores não chegam à consciência plena (terceira forma) por deficiência na telencefalização. O pensamento, mesmo nos macacos superiores, é rudimentar, apenas incipientemente simbólico, enquanto no ser humano, sem a capacidade para o simbolismo, não existiria o pensamento (verbal) e a linguagem. Seria exatamente o ocorrido segundo Segal (1978) nos esquizofrênicos. Neles haveria confusão entre o símbolo e o simbolizado, resultando no "pensamento concreto", por atacarem o pensar conforme procurou mostrar Wilfred Bion (1988). Esse ataque levaria o esquizofrênico a sentir o mundo como bizarro, a partir disso o autismo, os distúrbios do pensamento e da linguagem, a ambivalência e os delírios. Estes últimos freqüentemente como tentativas de voltar ao contato com a realidade. Vide Pacheco e Silva Filho (1989) reportando-se a vários psicanalistas atuais como Ogden, J. Grostein, H. Segal, H. Rosenfeld, W. Bios, M. Mahler e outros estudiosos do assunto.

$\mathrm{Na}$ conscientização ampliada, dependente do desenvolvimento maior da córtex, o Eu (self) recebe sua 
identidade e perspectiva histórica; torna-se auto-biográfico com passado, presente e futuro. Surgem em cena as funções superiores como a linguagem e a criatividade. Constrói-se a consciência moral na qual estão as relações sociais e sentimentos abstratos, como amor, honra e altruísmo. Citando ainda Damásio, Houzel ilustra como lesões nas estruturas do proto-self arrasam todos os níveis de consciência, comprovando ser a representação do corpo na mente o nível básico. Em ataques epiléticos ou ausências, a dissolução da consciência central leva junto a consciência ampliada. Esta, por sua vez, pode ser comprometida sem a segunda ser afetada, como em casos de amnésia e início da doença de Alzheimer. Vigília e consciência central não são sinônimos, como mostram ausências por disritmia cerebral, em que a pessoa acordada age automaticamente. Na hipnose, o hipnotizador se tornaria o superego do hipnotizado, podendo bloquear a consciência central e tornar o último, no transe profundo, um autômato sob suas ordens. Ainda, os achados do neurologista português levaram a conclusão de que tanto com quanto sem cérebro não há consciência, $\mathrm{o}$ corpo também é indispensável para a mesma. Houzel assinala como ver ou imaginar objetos ativa os mesmos neurônios, mostrando como são afetados de maneira idêntica por estímulos da realidade externa e interna.

A imaginação, para Houzel, seria a ativação interna da representação dos sentidos no cérebro. Como depende da experiência, esta é a matéria prima da imaginação. Mas, desculpe-me a autora, a imaginação (fantasia consciente) não é só representação dos sentidos no córtex. Talvez isso seja nos primatas que já a têm incipiente, nunca tão desenvolvida como em nós. No ser humano, a constituição do mundo interno simbólico individual não faria com que as redes neuronais ativem-se reciprocamente sem representações dos sentidos? Por puro autismo (ausência de relação objetal externa) construtivo, como vimos no autismo criativo, nas artes e nas ciências, diferente do autismo destrutivo das crianças autistas e esquizofrênicas.

Ainda, para Pugh (2002) as observações kleinianas da criança desenvolvendo a percepção de pessoas como objetos totais aos 4 meses (posição depressiva de M. Klein) parecem ser confirmadas pelo fato de nessa idade axônios dispensáveis no córtex serem eliminados. Campos sinápticos vão sendo integrados e a ponte inter-hemisférica é ampliada pela mielinização. Além disso, lesões na zona cortical heteromodal do hemisfério direito podem resultar em regressão para a percepção de objetos parciais.

Soussumi (2001), psicanalista de nossa sociedade, com vários estudos sobre a integração entre as neurociências e a psicanálise, refere-se a três tipos de memória:

1) Procedural, concernente ao cérebro reptiliano e ao dos mamíferos, armazenadora das primeiras recordações da humanidade e, no indivíduo, da infância.

2) Declarativa, concernente às lembranças.
3) Filogenética, referente ao estado mental primitivo e à fantasia inconsciente (representação mental do instinto, das pulsões, conforme M. Klein), tanto e principalmente dos impulsos destrutivos como dos eróticos (Thanatos e Eros de Freud). O complexo de édipo, para o autor, também poderia ser aqui incluído.

Del Nero (1997) assinala como programas prégravados inatos nos habilitam a ter uma pequena parcela da mente pré-instalada. São afirmações perfeitamente coincidentes com a pré-concepção de Wilfred Bion, atribuindo ao recém-nascido uma imagem de bom objeto (seio), a qual, em contato com o objeto, forma uma concepção. E mais adiante, escreve Del Nero, ter o indivíduo habilidades prévias (cerebrais) de estabelecer sincronia com os fatos do mundo. É uma confirmação neurocognitiva da idéia kleiniana do Ego incipiente no início da vida, não existindo o narcisismo primário de Freud.

Por sua vez, Basile (1998) assinala como parte da amígdala passou a ser tratada como "quase cortical", semelhante ao hipocampo e à cápsula do núcleo acumbente (amígdala expandida) que teriam importância primordial na explicação do comportamento em geral e da fisiopatologia psiquiátrica. Diria eu, importância primordial como efetores, mediadores psicossomáticos transformando a angústia em ansiedade, decorrentes não só de fatores externos (medos etc.), mas sobretudo de conflitos inconscientes do mundo interno, exigindo modificações do pensamento e do comportamento.

Koestler, A. (1967), citado por Persicano (2002) em pensamento semelhante às três formas de consciência de Damásio, refere-se aos "três cérebros" do ser humano: 1) $O$ reptiliano sensitivo-sensorial, incapaz de armazenar a experiência. 2) O mesocórtex, já existente nos mamíferos, tornando-os capazes de solucionar problemas elementares. Seria o sistema límbico ligado ao hipotálamo em mão dupla, filtrando as excitações antes de estas atingirem aquela estrutura. Permite a adaptação ao meio (externo) com base em experiências passadas. Avalia o significado emocional das experiências, pela inter-relação hipotálamohipófise-supra-renal. 3) O "terceiro cérebro" seria o néocórtex telencefálico, com predominância da parte auditiva sobre a visual. Na criatividade o mesocórtex é regressivamente incorporado ao neo-córtex em inter-relação. A cultura em cada grupo humano dependeria desse intercâmbio. Inicialmente passa de geração em geração oralmente, só posteriormente, com a escrita comunicativa, surgiriam novos valores individuais.

Na filogenia, o Homo habilis da Idade da Pedra seria ainda incapaz de usar a fantasia inconsciente e mesmo a consciente, daí o fato de não terem criatividade. Com a evolução surge o homem de Neanderthal, que já a tem. Em seguida surge o Homo sapiens, incluindo o CroMagnon. Surgem as várias raças, adorando deuses animais e outras ligadas às forças naturais. Ainda não existe 
qualquer liturgia religiosa. Apenas com o incremento da fantasia inconsciente, há 45 mil anos atrás, aparecem as primeiras manifestações artísticas. A dança seria a primeira forma de arte, já com um sentido erótico mais sofisticado e não quase só agressivo, como nos antropóides. Logo vem o desenho primitivo representativo. Como na criança (desenvolvimento ontogênico), seriam as primeiras manifestações de um psiquismo, da primeira consciência da subjetividade, com fantasias de onipotência (sopro criador), primeiro atribuído aos deuses, para o infante os pais, e depois em parte outorgado para si.

Com o desenho começa o planejamento de vida, com idéias do futuro. Os animais representados nas paredes das cavernas tornariam, pela fantasia inconsciente, mais fácil caçá-los. Desenhar, como depois fotografar, teria o significado inconsciente de se apoderar do objeto, desse modo fixado, congelado. $\mathrm{O}$ homem das cavernas gravou, esculpiu e pintou, progressivamente nessa ordem. Passa a não só observar a realidade externa como a reproduzi-la. Surgem os sonhos e as fantasias conscientes, não distinguidos no começo da realidade externa, tal qual ocorre na criança.

Pela arte o homem primitivo teria começado a refletir, dando um enorme salto no desenvolvimento cognitivo, desenvolvendo um cérebro com um excesso de possibilidades criativas, usadas para a solução de problemas mais complexos e para a arte. Com isso vão aparecendo as várias subjetividades no ser humano. Os padrões rígidos coletivos sendo alterados em várias culturas, com valores e modos de viver diversos.

\section{Conclusão}

Como tenho procurado mostrar nesta seção Ponto de Vista, a psicanálise atual contribui cada vez mais para compreensão da mente humana, seus distúrbios e seu tratamento. Por outro lado, as neurociências vêm confirmando inúmeros postulados psicanalíticos modernos, no estudo das funções cerebrais mais diferenciadas. Entretanto, os neurocientistas não podem mais deixar de lado as contribuições da ciência do inconsciente, como nós psicanalistas não desprezamos os desenvolvimentos dos conhecimentos das ciências cognitivas e das neurociências em geral.

Para muitos neurologistas e psiquiatras excessivamente organicistas, ainda somos uma espécie de filósofos, desligados da verdadeira ciência. Alcunha talvez válida para as escolas sectárias de psicanálise na sua ortodoxia. Fora destas, que apesar de tudo podem dar sua contribuição, a ciência psicanalítica já atinge hoje dimensões nada desprezíveis para a compreensão do ente humano na sua unidade e no seu relacionamento interpessoal, tanto na saúde como na doença.

Em artigo anterior nesta revista (2002) procurei focalizar mais detidamente o processo analítico. Ainda a respeito, gostaria de citar Kantrowitz(1995)e Schalker(1995), duas norte-americanas com dois trabalhos notáveis que revelam a percepção das mais sensíveis do jogo transferência-contratransferência. Na experiência emocional recíproca, o paciente evolui reavaliando suas vivências e o mesmo se dá com o analista, conforme vai percebendo como suas reações emocionais determinam e condicionam as do paciente. E com isso, o próprio analista evolui, não só como profissional, mas também como pessoa. As autoras, com muita sensibilidade e intuição, relatam como trabalham em um interjogo emocional profundamente humano entre duas pessoas, sem necessitar do jargão específico de qualquer das "escolas" psicanalíticas existentes. Aliás, em psicanálise, muitas vezes o mesmo termo é conceituado de várias maneiras por diferentes analistas, o que impede freqüentemente qualquer discussão criativa.

Finalizando, outro autor, o italiano Ferro (1996) possui as mesmas características, como demonstrou em seus seminários clínicos em nossa sociedade. São suas palavras: "Acredito que como analistas deveríamos mostrar, cada vez mais, para além das teorizações, aquilo que fazemos e como fazemos, na concretude da sessão". Aliás palavras muito semelhantes às de Bion (1973, 1974), em vários dos seus escritos e conferências, muitas das quais pronunciadas em São Paulo e Rio de Janeiro, tais como: "Na psicanálise, duas pessoas ousam se perguntar sobre coisas esquecidas e ignoradas, devendo ao mesmo tempo viver no presente, disso resulta ambas ficarem mais fortes mentalmente".

\section{Referências bibliográficas}

Basile, F. H. - Cerebromente - Uma Visão Contemporânea. Viver e Psicologia 71, 1998.

Bion, W. - Brazilian Lectures, vol. I e II. Imago, Rio de Janeiro, 1998. Bion, W. - Estudos Psicanalíticos Revisados. Imago, Rio de Janeiro.

Del Nero, H.S. - O Sítio da Mente. Collegium Cognitio, São Paulo, 1997. Ferro, A. - Antonino Ferro em São Paulo. Publicação da Sociedade Brasileira de Psicanálise de São Paulo, 1996.

Houzel, H.S. - O Cérebro Nosso de Cada Dia, 4ª ed. Viera \& Lent, Rio de Janeiro, 2002.

Kantrowitz, J.L. - The Beneficial Aspects of the Patient-analyst Match. Intern Journal Psychoan 76: 299.

Pacheco e Silva Filho, A.C. - Psicoses Funcionais. E. P. U, São Paulo, 1989

Pacheco e Silva Filho, A.C. - A Experiência Psicanalítica. Revista de Psiquiatria Clínica 29(5): 256-9.

Persicano, M.L.S. - Criatividade e Subjetivação do Cérebro e Arte na Criação Humana. Em Psicanálise, Arte e Estética. Organizadora Giovanna Bartucci. Imago, Rio de Janeiro, 2002.

Pugh, G. - Freud's Problem. Cognitive Neuroscience and Psychoanalysis. Intern Journal Psychoanalysis 83: 1375.

Redlich, F.; Bingham, J. - Nos Subterrâneos da Mente. Ibrasa, São Paulo, 1962.

Schalker, E. - The Psychoanalyst's Mind. Intern Journal Psychoan 76, 271,1995

SEgal, H. - On symbolism. Intern Journal Psychoan 59: 315-19, 1995.

Soussumi, Y. - Neuropsicanálise - A busca do Intercâmbio entre Neurociência e a Psicanálise. Revista Brasileira de Psicoterapia 3, (32), 2001. 